\title{
Multimodal Transport Network Optimization Considering Safety Stock under Real-Time Information
}

\author{
Ming-fei Chen $\mathbb{D}^{1},{ }^{1}$ Yan-qiu Liu, ${ }^{1}$ Yang Song $\mathbb{D},{ }^{1,2}$ Qi Sun $\mathbb{D}^{3},{ }^{3}$ and Chuang-chuang Cong ${ }^{4}$ \\ ${ }^{1}$ School of Management, Shenyang University of Technology, Shenyang 110870, China \\ ${ }^{2}$ Department of Economics and Management, Liaoning Finance Vocational College, Shenyang 110122, China \\ ${ }^{3}$ Antai College of Economics \& Management, Shanghai Jiao Tong University, Shanghai 200030, China \\ ${ }^{4}$ School of Foreign Studies, Shenyang University of Technology, Shenyang 110870, China
}

Correspondence should be addressed to Ming-fei Chen; cmfsy2014@163.com

Received 13 December 2018; Accepted 7 July 2019; Published 24 July 2019

Academic Editor: Emilio Jiménez Macías

Copyright (c) 2019 Ming-fei Chen et al. This is an open access article distributed under the Creative Commons Attribution License, which permits unrestricted use, distribution, and reproduction in any medium, provided the original work is properly cited.

\begin{abstract}
A production department and two distribution departments form a multimodal logistics supply network. The production department provides two ordering opportunities within one production cycle, and the real-time updates of demand information are required in the interval between two orders. Based on this, the paper studies the security inventory optimization problem of multimodal transport networks. On the basis of portraying the real-time information update process, the multimodal network optimization model without considering safety stock and the multimodal network optimization model considering safety stock are constructed, respectively, and the transshipment price and demand information of the intermodal network are updated. The parameters are analyzed for sensitivity. The analysis of examples shows that, on the one hand, with the update of demand information, the distribution department adopts the multimodal transport model with safety stock to improve the profit of the distribution department and the supply network. On the other hand, the production sector can meet market demand with a lower production scale, while the distribution department can effectively respond to stochastic demand through a multimodal model with safety stock.
\end{abstract}

\section{Introduction}

The shortening of the product-life-cycle and the expansion of the product sales area make the supply and demand imbalance more likely between regions [1-3]. With the update of demand information, enterprises can effectively deal with the mismatch between supply and demand through the multimodal transport logistics supply network, which can reduce inventory backlog and improve customer service level [48]. The imbalance of inventory control caused by mismatch between supply and demand can be handled by means of emergency ordering or by multimodal transport from the transshipment center [9-15]. The problem of emergency ordering is that the adjustment of production resources and the compression of the construction period will inevitably lead to high costs [16-20]. At the same time, in order to avoid over-supply and over-investment in production scale, the supply sector tends to limit the number of urgent orders in the distribution department to effectively develop production plans. Therefore, more and more enterprises tend to adopt multimodal transport to deal with the problem of supply and demand mismatch between regions [21]. Previous studies showed the significance of multimodal transport problems [1-20] and solutions [21] that can be improved from different perspectives. For instance, Mengliang et al. [1], Todd et al. [2], and Pałaszewskatkacz et al. [3] showed that demand information cannot be ignored; references [4-8] found the importance of requirements updates; researchers [9-15] emphasized that safety stock should be considered in multimodal transport; costs control should be considered in multimodal transportation optimization from literatures [16-20]; and Zhang et al. [21] provided a good method reference for multimodal transport network optimization problem. 


\section{Literature Review}

The main idea of multimodal transport is to make full use of the advantages of different modes for transport to improve economic efficiency [22-25]. Bektaş et al. [22] believed that the economic growth of logistics was due to the selection of appropriate transport mode. According to Forkenbrock [23], the external cost of intermodal trains is only $28 \%$ of truck transportation. In addition, because congestion costs are not included, there may be greater differences in external costs. Compared with land freight transport by European Commission [24], multimodal transport is not an energy-intensive mode of transport, which is conducive to the development of sustainable transport. Therefore, both academia and business fields are pushing forward the further research on the optimization of multimodal transport [25]. Multimodal transport researches mainly focus on two problems: one is the design of intermodal transport network, and the other is the control of performance.

Firstly, the design of intermodal transport network is about the choice of transportation mode and multimodal transport network model. Flodén et al. [26] found that the selection criteria of multimodal transport modes were mainly based on price but the premise was to ensure transport quality requirements. Meers et al. [27] discussed the determinants of Belgium's short-haul container transport mode selection and found that the reliability of alternatives needed to be considered and the information delay should be overcome. Winebrake et al. [28] focused on the transportation cost of the medium and heavy vehicle market in the United States and studied the idea that new technologies and policies would have an impact on the selection of vehicles. Al Enezy et al. [29] designed shipping network model to determine competitive prices. Lv et al. [30] considered simultaneous loading and unloading of cargo to/from containers for multimodal transport network; hence inventory information was also a significant point of multimodal transport. Jayaraman et al. [31] studied the multimodal transport problem of production and location allocation, in which raw material procurement and supplier decision-making were also included in the model. The choice of multimodal transport mode is also mainly based on transport process and operation environment, such as inventory and demand [26-31].

Secondly, the optimal control of performance for multimodal transport is a problem that the logistics department always pays attention to. Transportation cost is one of the main criteria for choosing transportation modes. Jolayemi et al. [32] proposed a profit maximization model of multiproduct and multifactory. Considering the cost of production, transportation, inventory, and warehouse location, the method of reducing model size was designed and the results were equivalent to the conventional model. Park [33] studied the integrated optimization of multiplant, multiproduct production-distribution transportation problems with limited production and transportation capacity. Ekşioğlu [34] showed that the ratio of fixed cost to variable cost, the length of planning scope, and the number of facilities in transport network would affect the performance of the algorithm. Akbalik et al. [35] designed the production-transportation integration problem of single factory and single product and compared the two intermodal transport strategies of punctuality and time window. De Matta et al. [36] solved the production-transportation integration problem of multiproducts and multifactories, in which each factory could use the direct shipment or combined delivery mode provided by the third party logistics company to minimize the fixed and variable production setup costs, inventory holding, and delivery costs. Liang et al. [37] studied the problem of multiproduct and multifactory intermodal transportation from the perspective of product backlog. Darvish et al. [38] considered the combined transportation of single product, multiplant, and multicycle and designed the branch and bound method to solve the transportation integration optimization problem by weighing the transportation cost and delivery speed.

What differentiates our paper from the above works of literature is that we consider safety stock under real-time information. To the best of our knowledge, there is no previous research studying this point for multimodal transport network optimization. From the above two mainstream perspectives, the shortcomings of existing research are analyzed. Previous researches neglected the role of inventory control in the process of transshipment in many ways [26-31]. Inventory is an important research parameter in transportation, because it concerns the quality of transport services. Although Flodén et al. [26] and Jayaraman et al. [31] are aware of this factor; there is no quantitative calculation in the model. In the process of multimodal transportation [26-31], more attention has been paid to transportation mode but safety inventory has been neglected. In addition, transport cost of multimodal transport is a statistic before or after the occurrence of logistics operations [32-38]. However, in the process of transshipment, the transit process will be accompanied by many additional changes in cost and demand information, which will affect the effectiveness of multimodal transport decisionmaking. Therefore, it is necessary to consider information updating in the optimization of multimodal transport [39, 40 , in order to ensure the significance of changing from unimodal transport to multimodal transport.

Therefore, we open up a new research direction for multimodal transport problem to combine real time information. What is more, we divide the mode of multimodal transport by the degree of urgency through the dimension of time. In addition, safety inventory is considered in our study to ensure that multimodal transport can be carried out effectively, thus stabilizing the quality of multimodal transport services.

\section{Problem Description}

Although Li et al. [40] combine demand information updating with safe multimodal transport, they only study the problem of multimodal transport safety inventory between two distribution departments at the same level, without considering the impact of transshipment on superior suppliers. This paper considers a multimodal transport supply network consisting of a production department $\mathrm{M}$ and two distribution departments $i(i=1,2)$. The two distribution departments make independent inventory decisions, but the production department is in a dominant position in the supply chain. 


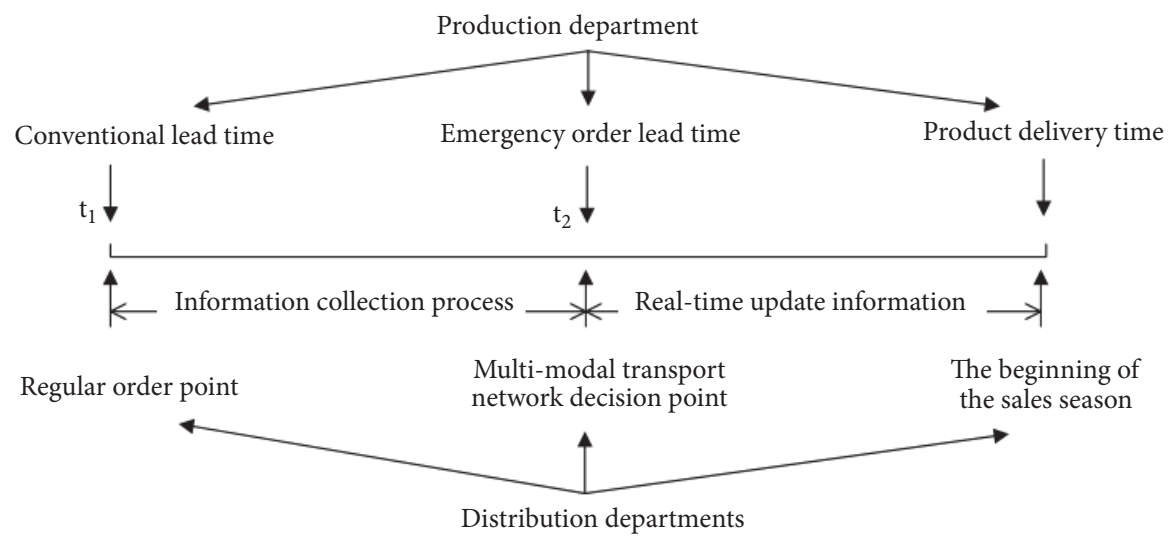

FIGURE 1: Ordering decision point diagram.

Reducing the size of the investment requires its distribution department to share its inventory level information, coordinated by the production department to share inventory through multimodal transport according to Forkenbrock [23]. The production department produces a seasonal new product, which provides two ordering opportunities to the distribution department, one for the regular ordering opportunity, and the other for the emergency ordering opportunity after optimizing the production cycle. Based on Choi et al. [39], we assume that the first regular order lead time is set as $t_{1}$, and the production department can meet all the ordering requirements of the distribution department. At the same time, the production department is optimized for resource operations and production cycles to provide emergency orders at a higher price during the emergency order lead time $t_{2}$.

As is shown in Figure 1, the regular order lead time is $t_{1}$ and the emergency order lead time is $t_{2}$. The distribution department determines the initial order quantity $Q_{i},(i=1,2)$ in the regular order lead time $t_{1}$ based on the sales experience of similar products in the past. The production department provides an opportunity to adjust the order quantity before the start of the sales season. The distribution department updates the demand forecast by collecting information during the period from $t_{1}$ to $t_{2}$ so as to adjust the order quantity at the moment $t_{2}$.

If the distribution department 1 updates the demand forecast and finds that the new forecast demand is larger than the original forecast, then it can be applied to the distribution department 2 for transfer or urgent order to the production department. Since the production department is in a dominant position in the supply chain, when the distribution department 2 predicts that the demand is less than the original forecast, the excess order quantity can be transferred at a predetermined transfer price.

After the demand information is updated, there will be three situations: (1) the demand forecast updated by the two distribution departments is increased; (2) the demand forecast updated by the two distribution departments is reduced; (3) the demand forecast updated by one distribution department is increased, while the other is reduced. Obviously, there is only the possibility of combined transshipment in the third situation. Therefore, this paper assumes that after the demand information is updated, the third situation occurs.

The production department is dominant in the supply chain and shares inventory information with the distribution departments. The production department can provide two ordering opportunities before the start of the sales season: one is for regular ordering opportunities, and the wholesale price is $w_{\mathrm{i}}$; the other is for emergency ordering opportunities, and the wholesale price is $v_{i}, v_{i}>w_{i}$.

The stochastic market demand faced by the distribution department is in line with the normal distribution and the market's selling price $r_{i}$ is exogenous. The forecasting error of the distribution department i to update the demand information and the lead time are logarithmic linear functions, i.e., $\ln d_{i}(t)=\alpha_{i 0}+\beta_{i} t$.

The transshipment price is a fixed value and is less than the emergency ordering cost, i.e., $\tau_{i j}<v_{i}$, to ensure priority for multimodal transport of the same-level distribution department; the transshipment price is greater than or equal to the sum of the residual value of the commodity unit and the unit transshipment cost, i.e., $\tau_{i j} \geq s_{i}+c_{i j}$. The sum of the sales price of the market unit and the unit penalty cost is greater than or equal to the sum of the residual value of the commodity unit and the unit transfer cost; that is, $r_{i}+p_{i} \geq$ $s_{j}+c_{j i}$, to ensure the realization of inventory multimodal transport between the distribution departments.

Residual value, wholesale price, transshipment price, emergency order price, and merchandise price of the unit commodity meet $s_{i} \leq w_{i} \leq \tau_{i j} \leq v_{i} \leq r_{i}$ to ensure the smooth implementation of the decision-making process. The description of each symbol is shown in Table 1.

\section{The Characterization of Real-Time Information Updates}

\subsection{Update Process of Real-Time Information}

Step 1. The production department provides a seasonal new product with a conventional wholesale price $w_{i}$, a production 
TABLE 1: The description of each symbol.

\begin{tabular}{|c|c|}
\hline Symbol & The description \\
\hline$r_{i}$ & The selling price per unit of goods, $i$ represents the distribution department $(i=1,2)$ \\
\hline$w_{i}$ & $\begin{array}{l}\text { The regular order cost per unit of merchandise, } w_{i}<r_{i} \text {, that is, the normal wholesale price of the production } \\
\text { department }\end{array}$ \\
\hline$s_{i}$ & The unit residual value of unsold goods, $s_{i}<w_{i}$ \\
\hline$p_{i}$ & The unit penalty cost for unmet demand \\
\hline$\tau_{i j}$ & $\begin{array}{l}\text { The unit combined transshipment price of goods from distribution department } j \text { to distribution department } i \text {, } \\
\tau_{i j}<r_{j},(j=1,2), j \neq i\end{array}$ \\
\hline$c_{i j}$ & $\begin{array}{l}\text { The unit transfer cost of goods from distribution department } \mathrm{j} \text { to distribution department } \mathrm{i} \text {, assuming that the } \\
\text { cost is borne by distribution department } \mathrm{j}, c_{i j}>w_{i}\end{array}$ \\
\hline$Q_{i}$ & Regular order quantity of distribution department i \\
\hline$D_{i}$ & $\begin{array}{l}\text { The initial random market demand is predicted by distribution department } \mathrm{i} \text {, and assume } D_{i} \text { obeys normal } \\
\text { distribution. }\end{array}$ \\
\hline$F_{D_{i}}(\cdot)$ & The cumulative distribution function of $D_{i}$ \\
\hline$f_{D_{i}}(\cdot)$ & The probability density function of $D_{i}$ \\
\hline$D_{i}^{l}$ & The random market demand of distribution department $\mathrm{i}$ after the demand information is updated \\
\hline$G_{D_{i}^{1}}(\cdot)$ & The cumulative distribution function of $D_{i}^{l}$ after the requirement information is updated \\
\hline$g_{D_{i}^{l}}(\cdot)$ & The density function of $D_{i}^{l}$ after the requirement information is updated \\
\hline$v_{i}$ & $\begin{array}{l}\text { The cost of an emergency order per unit of merchandise, } w_{i}<v_{i}<r_{i} \text {, that is, the emergency wholesale price of } \\
\text { the production department }\end{array}$ \\
\hline$Q_{i}^{l}$ & After the demand information is updated, the order quantity of distribution department $\mathrm{i}, i=1,2$ \\
\hline$Q_{i}^{v}$ & After the demand information is updated, distribution department i needs the quantity of urgent order, $i=1,2$ \\
\hline$\pi_{i}$ & The expected profit of distribution department i on regular orders \\
\hline$\pi_{i}^{l}$ & $\begin{array}{l}\text { The expected profit of distribution department i after the demand information is updated and inventory } \\
\text { adjustment is completed }\end{array}$ \\
\hline$t_{n}$ & The ordering time provided by the production department, $n=1,2$ \\
\hline$t$ & The lead time, $t_{1} \leq t \leq t_{2}$ \\
\hline$\pi_{m}$ & The profit of production department \\
\hline$c_{w}$ & Regular production cost of production department \\
\hline$c_{e}$ & Emergency production cost of production department \\
\hline
\end{tabular}

$\operatorname{cost} c_{w}$, an emergency wholesale price $v_{i}$, an emergency production cost $c_{v}$, and an exogenous market unified sales price $r_{i}$. If the distribution department chooses to distribute the new products, it should join the supply chain dominated by the production department so that the production department can coordinate.

Step 2. At $t_{1}$, the two distribution departments determine the initial order quantity $Q_{i}, i=1,2$ according to their respective experience information.

Step 3. Distribution department i collects the demand information signal $e_{i n}$ in the sales area during the period of $t_{1}-t_{2}$ and updates the demand forecast in the sales period.

Step 4. Distribution department i adjusts the order quantity according to the updated demand forecast and decides to change the inventory denoted as $\Delta Q_{i}$. Because this paper studies the situation that one distribution department predicts the increase of demand and another distribution department predicts the decrease of demand, suppose $\Delta Q_{i} \geq 0$, that is, it needs to supplement the regular order quantity, and $\Delta Q_{3-i}<0$, that is, it needs to transship the regular order quantity. Distribution department $i$, which needs to replenish the order quantity, first replenishes it through the transshipment from other distribution departments. The transshipment price led by the production department is $\tau_{i j}$, and the transshipment quantity is $T_{i j}=\min \left(\Delta Q_{i},-\Delta Q_{3-i}\right)$; the insufficient part is replenished through the emergency order from the supplier; the emergency order cost is $v_{i}$, the emergency order quantity is $Q_{i}^{v}$, and there is $\Delta Q_{i}=T_{i j}+Q_{i}^{v}$. All orders arrive before the start of the sale.

Step 5. After the start of the sales season, the actual demand of the distribution department has been realized. Unmet demand will lead to loss of sales and penalty cost $s_{i}$, and surplus inventory will get residual value $v_{i}$, so $s_{i} \leq w_{i} \leq T_{i j} \leq$ $v_{i} \leq r_{i}$.

4.2. Implementation of Requirement Information Update. By optimizing the emergency ordering opportunities provided by production resources, the production department gives 
the distribution department the possibility to adjust the ordering quantity. The closer it is to the sales period, the more sufficient market information the distribution department will collect, and the more accurate the market demand forecast will be. Assuming that the lead-time is $t\left(t_{1} \leq t \leq t_{2}\right)$, the logarithmic linear function relationship $\ln d_{i}(t)=\alpha_{i 0}+$ $\beta_{i} t$, namely, $d_{i}(t)=\alpha_{i} e^{\beta_{i} t}\left(\alpha_{i}=e^{\alpha_{i 0}}\right)$, is used to express the relationship between the demand forecast error and the leadtime, and $d_{i}(t)$ is used to represent the forecast error, which is a function of the lead-time $t$.

Demand uncertainty includes two levels.

(1) The randomness of requirements inherent in the product itself: the distribution of demand $D_{i}$ obeys the normal distribution of mean $M_{i}$ and variance $\sigma_{i}^{2}$, that is, $f_{i}(d) \sim \mathrm{N}\left(M_{i}, \sigma_{i}^{2}\right)$. For illustration, let $d_{i}(t)=\sigma_{i}$.

(2) The demand expectation $M_{i}$ itself has randomness, which obeys the normal distribution of mean $\mu_{i}$ and variance $\tau_{i}^{2}$, namely, $g_{i}(m) \sim \mathrm{N}\left(\mu_{i}, \tau_{i}^{2}\right)$. At the lead time $t$, the information collected during the period of $t_{1}-t_{2}$ will be transformed into a demand estimate of $e_{i n}$.

So we get a conditional distribution $g\left(M_{i} \mid e_{i n}\right) \sim$ $\mathrm{N}\left(\mu_{i}\left(e_{i n}\right), 1 / \rho_{i}\left(t_{n}\right)\right)$, thereinto $\rho_{i}\left(t_{n}\right)=1 / \sigma_{i}^{2}+1 / \tau_{i}^{2}, \mu_{i}\left(e_{i n}\right)=$ $\left(\sigma_{i}^{2} \mu_{i}+\tau_{i}^{2} e_{i n}\right) /\left(\sigma_{i}^{2}+\tau_{i}^{2}\right)$. According to Bayesian theorem, when the lead time is $t$, the distribution of the updated demand information is as follows: $f_{i}^{l}\left(D_{i} \mid e_{i n}\right) \sim \mathrm{N}\left(\mu_{i}\left(e_{i n}\right), \sigma_{i}^{2}+1 /\right.$ $\left.\rho_{i}\left(t_{n}\right)\right)$. Let $\mu_{t n}=\mu_{i}\left(e_{i n}\right), \sigma_{t n}^{2}=\sigma_{i}^{2}+1 / \rho_{i}\left(t_{n}\right), D_{i n}=D_{i} \mid e_{i n}$, that is, $f_{i}^{l}\left(D_{i n}\right) \sim N\left(\mu_{i n}, \sigma_{i n}^{2}\right)$.

\section{The Optimization Model of Multimodal Transport Network under Real-Time Information}

5.1. Multimodal Transport Network Model without Safety Inventory. After the distribution department updates the demand information, the predicted market demand is satisfied by the emergency order provided by the production department, and the two distribution departments are not allowed to be satisfied through multimodal transportation.

When ordering in advance of emergency order, the distribution department 1 obtains the market demand information $e_{1 n}$ observed during the period $t_{1}-t_{2}$, updates the mean value $\mu_{1}$, and obtains the new market demand probability density function $g_{D_{1}^{l}}(\cdot)$ and cumulative distribution function $G_{D_{1}^{l}}(\cdot)$. At this time, in the supply chain dominated by the production sector, multimodal transport between the downstream distribution departments is not allowed. Therefore, for the distribution department 1 , the order quantity $Q_{1}$ at the lead time $t_{1}$ of the conventional order has been known, and the expected demand of the time point $t_{2}$ for distribution department 1 increases. That is to say, $D_{1}{ }^{l} \geq D_{1}$ and $\mu_{1}^{l} \geq \mu_{1}$; when the profit of the distribution department 1 is $\pi_{i}^{l}$, there are

$$
\begin{aligned}
\pi_{1}^{l}= & r_{1} \min \left\{Q_{1}^{l}, D_{1}^{l}\right\}+s_{1}\left(Q_{1}^{l}-D_{1}^{l}\right)^{+} \\
& -p_{1}\left(D_{1}^{l}-Q_{1}^{l}\right)^{+}-v_{1}\left(Q_{1}^{l}-Q_{1}\right)-w_{1} Q_{1}
\end{aligned}
$$

Take the first derivative and set it equal to 0 to get the optimal inventory

$$
Q_{1}^{* l}=G_{D_{1}}^{-1}\left(\frac{r_{1}+p_{1}-v_{1}}{r_{1}+p_{1}-s_{1}}\right)
$$

After the update of demand information, the expected profit of distribution department 1 is

$$
\begin{aligned}
E\left(\pi_{1}^{l}\right)= & \int_{0}^{Q_{1}^{l}}\left(r_{1}+p_{1}-s_{1}\right) D_{1}^{l} f(x) d x \\
& -\int_{0}^{Q_{1}^{l}}\left(r_{1}+p_{1}-s_{1}\right) Q_{1}^{l} f(x) d x \\
& +\left(r_{1}+p_{1}-v_{1}\right) Q_{1}^{l}-p_{1} \mu+\left(v_{1}-w_{1}\right) Q_{1}
\end{aligned}
$$

In the formula, $\mu$ is the mean of probability density function $g_{D_{1}^{l}}(\cdot)$, and the optimal inventory is determined when ordering $Q_{1}$ at a time point $t_{1}$.

At the time point $t_{1}$, according to previous experience, the distribution department 1 estimates the probability density function $f_{D_{1}}(\cdot)$ of market demand for products and cumulative demand distribution $F_{D_{1}}(\cdot)$, and accordingly orders $Q_{1}$ from the production department. At this time, the profit of the distribution department 1 is

$$
\begin{aligned}
\pi_{1}= & r_{1} \min \left\{Q_{1}, D_{1}\right\}+s_{1}\left(Q_{1}-D_{1}\right)^{+} \\
& -p_{1}\left(D_{1}-Q_{1}\right)^{+}-w_{1} Q_{1}
\end{aligned}
$$

The first derivative to $Q_{1}$ is obtained, and the first derivative is zero to obtain the optimal inventory:

$$
Q_{1}^{*}=F_{D_{1}}^{-1}\left(\frac{r_{1}+p_{1}-w_{1}}{r_{1}+p_{1}-s_{1}}\right)
$$

The expected demand of time-point $t_{2}$ for distribution department 2 decreases, and its profit is $\pi_{2}^{l}$, because the production department does not provide repurchase; even if the distribution department 2 collects demand information and updates the demand forecast, the surplus goods ordered at time $t_{1}$ cannot be returned to the production department. Therefore, the order quantity of distribution department 2 is still the order quantity at the time $t_{1}$. At the regular ordering time point $t_{1}$, the profit $\pi_{2}$ of the distribution department 2 ordering according to the demand distribution function $F_{D_{2}}(\cdot)$ determined by previous experience is as follows:

$$
\begin{aligned}
\pi_{2}= & r_{2} \min \left(Q_{2}, D_{2}\right)+s_{2}\left(Q_{2}-D_{2}\right)^{+} \\
& -p_{2}\left(D_{2}-Q_{2}\right)^{+}-w_{2} Q_{2}
\end{aligned}
$$

Take the first derivative of the equation, and set it equal to 0 , and get the optimal inventory:

$$
Q_{2}^{*}=F_{D_{2}}^{-1}\left(\frac{r_{2}+p_{2}-w_{2}}{r_{2}+p_{2}-s_{2}}\right)
$$

After updating the information at the time point $t_{2}$, the new market demand probability density function $g_{D_{2}}(\cdot)$ 
and cumulative distribution function $G_{D_{2}}(\cdot)$ are obtained. Distribution department 2 shall sell the quantity $Q_{2}^{*}$ of products ordered at the time point $t_{1}$, and the profit $\pi_{2}^{l}$ at the time point $t_{2}$ shall be as follows:

$$
\begin{aligned}
\pi_{2}^{l}= & r_{2} \min \left(Q_{2}^{*}, D_{2}^{l}\right)+s_{2}\left(Q_{2}^{*}-D_{2}^{l}\right)^{+} \\
& -p_{2}\left(D_{2}^{l}-Q_{2}^{*}\right)^{+}-w_{2} Q_{2}^{*}
\end{aligned}
$$

That is,

$$
\begin{aligned}
\pi_{2}^{l}= & \int_{0}^{\mathrm{Q}_{2}^{*}}\left(r_{2}+p_{2}-s_{2}\right) D_{2}^{l} f(x) d x \\
& -\int_{0}^{\mathrm{Q}_{2}^{*}}\left(s_{2}-r_{2}-p_{2}\right) Q_{2}^{*} f(x) d x \\
& +\left(r_{2}+p_{2}-w_{2}\right) Q_{2}^{*}-p_{2} \mu_{2}
\end{aligned}
$$

In the formula, $\mu_{2}$ is the mean of the updated market demand probability density function $g_{D_{2}^{l}}(\cdot)$ and $Q_{2}^{*}$ is the optimal inventory at $t_{1}$.

The total production quantity of the production department in two stages is $\left(Q_{1}^{l}+Q_{2}^{*}\right)$. The profit is $\pi_{m}$. The production is $Q_{1}^{*}+Q_{2}^{*}$ at $t_{1}$ :

$$
\pi_{m}=\left(w_{1}-c_{w}\right)\left(Q_{1}^{*}+Q_{2}^{*}\right)+\left(v_{1}-c_{e}\right)\left(Q_{1}^{* l}-Q_{1}^{*}\right)
$$

In the formula, the first item on the right side of the equal sign is the profit at the time $t_{1}$ for regular ordering, and the second item is the profit at the time point $t_{2}$.

5.2. Multimodal Transport Network Model Considering Security Inventory after Demand Information Updating. After the distribution department updates the demand information, the predicted market demand allows the distribution department to meet the demand through multimodal transport, and the insufficient part is met through the emergency order provided by the production department. At this time, the sales season has not started, and there is no actual shortage of goods, so the multimodal transport belongs to the safe multimodal transport. $T_{i j}$ denotes the quantity of the distribution department i transported to the distribution department $j . T_{i j}$ is the smaller quantity of the expected replenishment inventory quantity of the distribution department $i$ and the expected surplus inventory quantity of the distribution department $J$ after the demand information is updated, that is, $T_{i j}^{*}=\min \left\{\left|Q_{i}^{l}-Q_{i}\right|,\left|Q_{j}^{l}-Q_{j}\right|\right\}$. The part that distribution department $i$ failed to meet through transshipment is supplemented by emergency orders, and the number of emergency orders is $Q_{i}^{v}=Q_{i}^{l}-T_{i j}$.

Distribution department collects market demand information and updates market demand forecast at the interval of two order points provided by production department. At $t_{2}$, the order quantity is adjusted. At $t_{1}$, the regular order quantity $Q_{2}$ determined by experience is known. After the order quantity is adjusted, all orders will reach the distribution department before the selling season. At the end of the sales season, the profit function of the distribution department $\mathrm{i}$ is $\pi_{i}^{l}$, without losing generality. Assume that the expected demand of the distribution department 2 , after updating the demand information, decreases. In the process of adjusting the order quantity, it is necessary to transfer a part of the order quantity to the distribution department 1 . The number of transshipments is $T_{21}$. At this time, the profit of the distribution department 2 is as follows:

$$
\begin{aligned}
\pi_{2}^{l}= & r_{2} \min \left\{Q_{2}^{*}-T_{21}, D_{2}^{l}\right\}+s_{2}\left(Q_{2}^{*}-T_{21}-D_{2}^{l}\right)^{+} \\
& -p_{2}\left(D_{2}^{l}-Q_{2}^{*}+T_{21}\right)^{+}+\left(\tau_{21}-c_{21}\right) T_{21}-w_{2} Q_{2}^{*}
\end{aligned}
$$

The expected profit of distribution department 2 is

$$
\begin{aligned}
& E\left(\pi_{2}^{l}\right)=\int_{0}^{Q_{2}^{*}-T_{21}}\left[r_{2} * D_{2}^{l}+s_{2}\left(Q_{2}^{*}-T_{21}-D_{2}^{l}\right)\right. \\
& \left.\quad+\left(\tau_{21}-c_{21}\right) T_{21}-w_{2} Q_{2}^{*}\right] f_{D_{2}^{l}}(x) d x \\
& \quad+\int_{Q_{2}^{*}-T_{21}}^{+\infty}\left[r_{2} *\left(Q_{2}^{*}-T_{21}\right)-p_{2}\left(D_{2}^{l}-Q_{2}^{*}-T_{21}\right)\right. \\
& \left.\quad+\left(\tau_{21}-c_{21}\right) T_{21}-w_{2} Q_{2}^{*}\right] f_{D_{2}^{l}}(x) d x
\end{aligned}
$$
get

Take the first derivative of $\mathrm{E}\left(\pi_{2}^{l}\right)$ with respect to $T_{21}$, and

$$
G_{D_{2}}\left(Q_{2}^{*}-T_{21}\right)=\frac{r_{2}+p_{2}-\tau_{21}+c_{21}-w_{2}}{r_{2}+p_{2}-s_{2}}
$$

That is, the optimal inventory of distribution department 2 after demand information is updated is

$$
Q_{2}^{l *}=Q_{2}^{*}-T_{21}=G^{-1}{ }_{D_{2}}\left(\frac{r_{2}+p_{2}-\tau_{21}+c_{21}-w_{2}}{r_{2}+p_{2}-s_{2}}\right)
$$

In the formula, $T_{21}$ is the optimal turnover of distribution department 2. As for distribution department 1, its expected demand increases, thus requiring multimodal transportation from distribution department 2 . If the insufficient parts are urgently ordered from the production department, the profit of distribution department 1 after the demand information is updated is

$$
\begin{aligned}
\pi_{1}^{l}= & r_{1} \min \left\{Q_{1}^{*}+T_{21}+Q_{1}^{V}, D_{1}^{l}\right\} \\
& +s_{1}\left(Q_{1}^{*}+T_{21}+Q_{1}^{V}-D_{1}^{l}\right)^{+} \\
& -p_{1}\left(D_{1}^{l}-Q_{1}^{*}-T_{21}-Q_{1}^{V}\right)^{+}-\tau_{21} T_{21}-v_{1} Q_{1}^{v} \\
& -w_{1} Q_{1}^{*}
\end{aligned}
$$

The expected profit of distribution department 1 is

$$
\begin{aligned}
& E\left(\pi_{1}^{l}\right)=\int_{0}^{Q_{1}^{*}+T_{21}+Q_{1}^{V}}\left[r_{1} * D_{1}^{l}\right. \\
& \quad+s_{1}\left(Q_{1}^{*}+T_{21}+Q_{1}^{V}-D_{1}^{l}\right)-\tau_{21} T_{21}-v_{1} T_{21} \\
& \left.\quad-w_{1} Q_{1}^{*}\right] f_{D_{1}^{l}}(x) d x+\int_{Q_{1}^{*}+T_{21}+Q_{1}^{V}}^{+\infty}\left[r_{1}\right.
\end{aligned}
$$




$$
\begin{aligned}
& *\left(Q_{1}^{*}+T_{21}+Q_{1}^{V}\right)-p_{1}\left(D_{1}^{l}-Q_{1}^{*}-T_{21}-Q_{1}^{V}\right) \\
& \left.-\tau_{21} T_{21}-v_{1} T_{21}-w_{1} Q_{1}^{*}\right] f_{D_{1}^{l}}(x) d x
\end{aligned}
$$

By taking the first derivative with respect to $T_{21}$, we can get

$$
G_{D_{1}^{l}}\left(Q_{1}^{*}+T_{21}+Q_{1}^{V}\right)=\frac{r_{1}+p_{1}-\tau_{21}}{r_{1}+p_{1}-s_{1}}
$$

That is, the optimal inventory of distribution department 1 after demand information is updated is

$$
Q_{1}^{l *}=Q_{1}^{*}+T_{21}+Q_{1}^{V}=G_{D_{1}^{l}}^{-1}\left(\frac{r_{1}+p_{1}-v_{1}}{r_{1}+p_{1}-s_{1}}\right)
$$

Among the formulas, $Q_{1}^{*}$ and $Q_{2}^{*}$ are the optimal order quantity determined by the historical experience of the distribution departments 1 and 2 before the update of demand information.

Since the actual inventory transfer amount of distribution department 2 is the same as the actual inventory transfer amount of distribution department 1 , it can be obtained by combining (14) and (18):

$$
\begin{aligned}
Q_{1}^{V}= & G^{-1}{ }_{D_{2}}\left(\frac{r_{2}+p_{2}-\tau_{21}+c_{21}-w_{2}}{r_{2}+p_{2}-s_{2}}\right) \\
& +G_{D_{1}^{l}}^{-1}\left(\frac{r_{1}+p_{1}-v_{1}}{r_{1}+p_{1}-s_{1}}\right)-Q_{1}^{*}-Q_{2}^{*}
\end{aligned}
$$

When $Q_{1}^{V}>0$, after the demand information of the two distribution departments is updated, the sum of the predicted demand exceeds the sum of the regular order quantity, so it is necessary to order products urgently from the production department at the point of emergency order to meet the expected increased demand. Assume that the demand of distribution department 1 increases while the demand of distribution department 2 decreases. $Q_{1}^{V}>0$ indicates that the surplus inventory of distribution department 2 has been transferred out completely. When distribution department 1 receives the transferred products, the inventory is still insufficient and it needs to place an urgent order from the production department. The actual transshipment at this point is $T_{21}^{*}=T_{21}$.

When $Q_{1}^{V}<0$, the sum of the regular orders of the two distribution departments is greater than the sum of the expected demand after the update of the demand information, so there is no need to place an urgent order from the production department. Assume that the demand of distribution department 1 increases while the demand of distribution department 2 decreases. $Q_{1}^{V}>0$ shows that if all the surplus inventory of distribution department 2 is transferred out, distribution department 1 will exceed the optimal inventory when receiving the transshipped products after updating its own demand information. At this time, $\left|Q_{1}^{V}\right|$ means the surplus order inventory of distribution department 1 ; that is to say, all the inventory of distribution department 1 will be satisfied through transshipment, while distribution department 2 will only meet the surplus order inventory of distribution department 1 through transshipment. Some surplus stock is transferred out. In this case, the optimal inventory of the distribution department 2 is $Q_{2}^{*}-T_{21}$, the actual inventory is $Q_{2}^{*}-T_{21}+\left|Q_{1}^{V}\right|$, and the actual transshipment is $Q_{1}^{V}>0$.

After the demand information is updated, the profit of the production department is

$$
\begin{aligned}
\pi_{m}= & \left(w_{1}-c_{w}\right)\left(Q_{1}^{*}+Q_{2}^{*}\right) \\
& +\left(v_{1}-c_{e}\right)\left(Q_{1}^{l *}+Q_{2}^{1 *}-Q_{2}^{*}-Q_{2}^{* l}\right)^{+}
\end{aligned}
$$

\section{Discussions on the Case Study}

6.1. Parameter Setting. This paper takes the agency distribution department in a certain area as an example to verify. Female clothing products produced by the company belong to typical seasonal products. The exclusive agency sales model is adopted in a certain area. Considering the scale of investment control, multimodal transportation is allowed between agency distribution departments in a certain area. Because of the trade secrets involved, the relevant production and sales data of the women's long skirt products launched by the company are processed accordingly. At the same time, referring to the needs of Choi et al. [39] and Li et al. [40] for the calculation of relevant parameters, the relevant data are set as follows.

The retail price of the product market is $r_{1}=r_{2}=$ 20. The regular wholesale price provided by the production department is $w_{1}=w_{2}=10$. After the end of the selling season, the residual value of the unsold products by the distribution department is $s_{1}=s_{2}=2$. The unit penalty cost for not meeting the demand is $p_{1}=p_{2}=$ 5 . The regular ordering time provided by the production department is 200 days, and the emergency ordering time is 50 days. Emergency wholesale price is $v_{1}=v_{2}=15$. When transshipment is allowed, the unit transshipment price between distribution departments is $\tau_{12}=\tau_{21}=12$, the unit transshipment cost is $c_{12}=c_{21}=8$, the conventional production cost of production departments is $c_{w}=5$, and the economic production cost of production department is $c_{e}=14$. The function $d_{i}(t)=\alpha_{i} e^{\beta_{i} t}$ used represents the relationship between demand forecasting error and lead time. The parameters of distribution department 1 are set as $\alpha_{1}=$ 150, $\beta_{1}=0.003, \mu_{1}=2000$, and $\tau_{1}=300$, and the parameters of distribution department 2 are set as $\alpha_{2}=100, \beta_{2}=0.005$, $\mu_{2}=3000$, and $\tau_{2}=200$.

Based on the above examples, the numerical results under safe and non-transshipment conditions are obtained at the time of $e_{1 n}=2700$ and $e_{2 n}=3000$, respectively, as shown in Table 2. Table 2 shows that whether safe transshipment is allowed or not, the update of demand information always increases the total profit of the system consisting of one production department and two distribution departments. However, in the case of no safe transshipment, the increase of profits only comes from the distribution department 1 and the production department, while in the case of safe transshipment, the profits of the distribution department 1 , the 


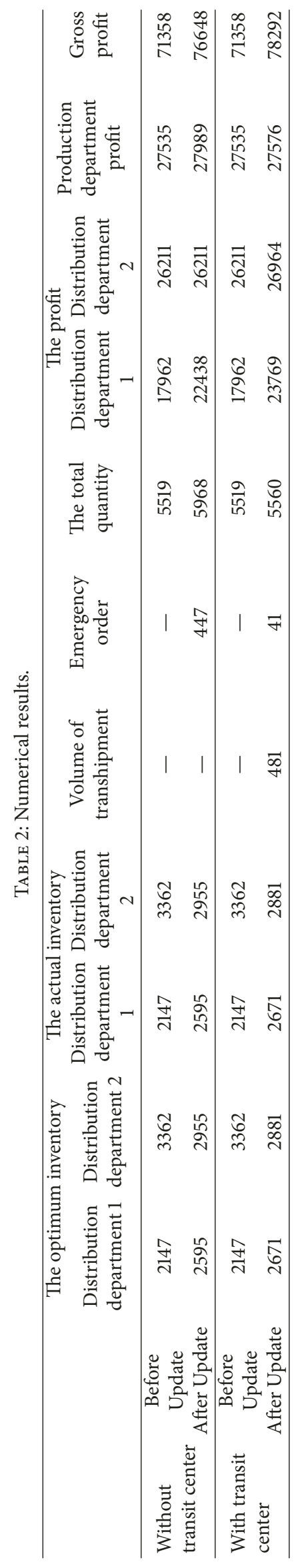


distribution department 2 , and the production department all increase.

Comparing the total profits of distribution department 1 , distribution department 2 , and production department under the conditions of permitting safe transshipment and not permitting transshipment as well as the profits of distribution department 1 , distribution department 2 , and production department after renewal of demand information, we can see that the total profits of distribution department 1 and distribution department 2 increase more greatly when safe transshipment is allowed, and the profits of distribution department 1 and distribution department 2 are higher than those with no safe transshipment allowed. The profits of the production department have declined slightly. This is because in the case of allowing safe transshipment, emergency orders reduce, and production departments use less production scale to meet customer needs. Therefore, although the profit of the production department has declined slightly, the corresponding investment in the scale of production has also declined. At the same time, considering the high production cost of the products urgently produced by the production department, the profit decline is not large.

From the above results, we can see that the production department can meet the market demand by optimizing the production allocation factors, providing emergency orders in addition to conventional orders, and allowing the downstream distribution department to transship. The time interval between routine order and emergency order makes it possible for the distribution department to update market demand information. By updating demand information, the distribution department can forecast demand more accurately, which is conducive to the distribution department to do a good job of response measures in advance, prevent the occurrence of shortage, and thus improve the overall profit of the system.

6.2. Analysis of the Impact of $\tau_{i j}$ on Decision Making. As can be seen from Table 2, under the condition of updating demand information, the optimal inventory changes of distribution department 1 and distribution department 2 which allow safe transshipment are greater than that with non-transshipment, indicating that transshipment price will affect the ordering decision of distribution department. In order to further analyze the influence of transshipment price on demand information updating of distribution department, the data of distribution department and production department at six different transshipment prices are calculated, which are $\tau_{i j}=$ $10.0,10.5,11.0,11.5,12.0$, and 12.5 , respectively. The results are shown in Table 3.

As can be seen from Table 3, with the increase of transshipment price, the optimal inventory, actual inventory, and profit of distribution department 1 , as well as the emergency order quantity, all show a downward trend; the optimal inventory quantity of distribution department 2 shows a downward trend, while its profit shows an upward trend; the total order quantity and the profit of production department both show a downward trend and tend to be at $\tau_{i j}=$ 13. The transshipment volume of distribution department 2 shows an upward trend, but the actual inventory volume of distribution department 2 and the actual transshipment volume between the two distributors show an upward trend first and then a downward trend. From the profit point of view, with the increase of transshipment price, the profit of distribution department 1 shows a downward trend, while that of distribution department 2 shows an upward trend; when transshipment is not enough to make up for the forecast demand of distribution department 1, emergency orders appear. Because of the small profit of emergency order of production department, the profit of production department also shows a downward trend. When transshipment can fully meet the demand of distribution department 1 without urgent order, the production department does not need emergency production, and the profit remains unchanged. This fully illustrates that the transfer under the conditions of updating of information led by the production department will help the downstream distribution department to increase profits, facilitate the whole supply system to meet market demand with a smaller production scale, and avoid excessive production or blindly expand the production scale of the production department.

\section{Conclusions}

Considering a multimodal supply chain system consisting of one production department and two distribution departments, the production department provides two orders. This paper discusses how to update the demand information by using the time interval between two orders. On the basis of describing the updating of demand information, the multimodal transportation model considering safe inventory and the multimodal transportation model without considering safe inventory are constructed, respectively. The main conclusions are as follows.

Firstly, the distribution department updates the demand information by means of the time interval between the two order points provided by the production department. Compared with not allowing safe multimodal transport, allowing safe multimodal transport can improve the overall profit of the supply chain composed of the production department and the distribution department.

Secondly, in the case of allowing safe multimodal transport, the production department can use a lower production scale to meet market demand, and the distribution department can better respond to stochastic demand through transshipment or emergency ordering after the demand information is updated.

Thirdly, with the increase of transshipment price, the order quantity of distribution department is decreasing, but the transshipment quantity is increasing. On the premise that the demand forecasting error is logarithmic linear with lead time, the updating parameters of demand information have a great influence on the demand forecasting error. The larger the demand forecasting error is, the more likely the distribution department will be to reduce the order quantity, which results in the decrease of transshipable quantity and the increase of emergency order quantity.

Finally, this paper discusses the renewal of demand information under the logarithmic linear relationship between 


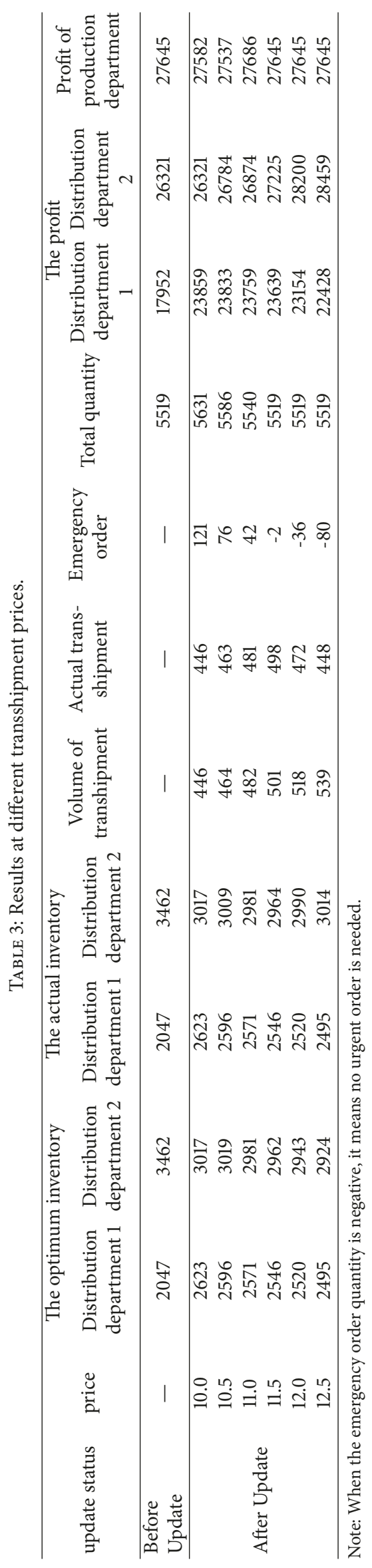


demand forecasting error and lead time and carries out the corresponding parameter analysis. In the future, it is necessary to further study the impact of security multimodal transport on supply chain decision-making under different demand forecasting models from different distribution departments and other updating modes of demand information. In addition, the multimodal transport strategy of the production department, distributor, and distribution department with real products under the Internet environment is also worth discussing.

\section{Data Availability}

The [data.xlsx] data used to support the findings of this study have been deposited in the [https://pan.baidu.com/s/ 1fz4M0Bjc8KJkPFSTgRXe0A (password: pm0t)].

\section{Conflicts of Interest}

The authors declare that they have no conflicts of interest.

\section{Acknowledgments}

This paper is supported by the National Natural Science Foundation of China (No. 70431003), and Scientific Research Foundation Program of the Educational Department of Liaoning Province China (No. JYT2019-02), and ScienceTechnology Planning Program of Shenyang, China (No. 18004-2-27).

\section{References}

[1] D. A. Serel, "Optimal ordering and pricing in a quick response system," International Journal of Production Economics, vol. 121, no. 2, pp. 700-714, 2009.

[2] C.-F. Chien, Y.-J. Chen, and J.-T. Peng, "Manufacturing intelligence for semiconductor demand forecast based on technology diffusion and product life cycle," International Journal of Production Economics, vol. 128, no. 2, pp. 496-509, 2010.

[3] G. R. Dowling, "Product life cycle traps: strategic planning and shortening PLCs," Journal of Brand Management, vol. 4, no. 2, pp. 119-132, 1996.

[4] A. Magnier, N. Kalaitzandonakes, and D. J. Miller, "Product life cycles and innovation in the US seed corn industry," International Food and Agribusiness Management Review, vol. 13, no. 3, pp. 17-36, 2010.

[5] M. W. Asad and R. Dimitrakopoulos, "Implementing a parametric maximum flow algorithm for optimal open pit mine design under uncertain supply and demand," Journal of the Operational Research Society, vol. 64, no. 2, pp. 185-197, 2013.

[6] C. Mitchell, D. Bauknecht, and P. Connor, "Effectiveness through risk reduction: a comparison of the renewable obligation in England and Wales and the feed-in system in Germany," Energy Policy, vol. 34, no. 3, pp. 297-305, 2006.

[7] S. Afshin Mansouri, D. Gallear, and M. H. Askariazad, "Decision support for build-to-order supply chain management through multiobjective optimization," International Journal of Production Economics, vol. 135, no. 1, pp. 24-36, 2012.

[8] J. Xu, Q. Bai, L. Xu, and T. Hu, "Effects of emission reduction and partial demand information on operational decisions of a newsvendor problem," Journal of Cleaner Production, vol. 188, pp. 825-839, 2018.

[9] S. Gu, H. Guo, and Y. Su, "Research on supply chain coordination and profit allocation based on altruistic principal under bilateral asymmetric information," Discrete Dynamics in Nature and Society, vol. 2018, Article ID 2302434, 15 pages, 2018.

[10] H. L. Lee, "A multi-echelon inventory model for repairable items with emergency lateral transshipments," Management Science, vol. 33, no. 10, pp. 1302-1316, 1987.

[11] S. Axsäter, "Evaluation of unidirectional lateral transshipments and substitutions in inventory systems," European Journal of Operational Research, vol. 149, no. 2, pp. 438-447, 2003.

[12] M. Li, X. Wang, Q. Sun, and Z. Yang, "Research on allocation strategies of multimodal transportation for emergency resources based on robust optimization," Journal of the China Railway Society, vol. 39, no. 7, pp. 1-9, 2017.

[13] K. H. Todd, "A review of current and emerging approaches to pain management in the emergency department," Pain \& Therapy, vol. 6, no. 2, pp. 193-202, 2017.

[14] A. Pałaszewska-Tkacz, S. Czerczak, and K. Konieczko, "Chemical incidents resulted in hazardous substances releases in the context of human health hazards," International Journal of Occupational Medicine and Environmental Health, vol. 30, no. 1, pp. 95-110, 2017.

[15] F. Biondi, D. L. Strayer, R. Rossi, M. Gastaldi, and C. Mulatti, "Advanced driver assistance systems: using multimodal redundant warnings to enhance road safety," Applied Ergonomics, vol. 58, pp. 238-244, 2017.

[16] F. L. Luan, H. Zhang, D. E. Schaubel et al., "Comparative risk of impaired glucose metabolism associated with cyclosporine versus tacrolimus in the late posttransplant period," American Journal of Transplantation, vol. 8, no. 9, pp. 1871-1877, 2008.

[17] D. N. D. C. Perio, "Periodontal bone regeneration and the Er,Cr:YSGG laser: a case report," The Open Dentistry Journal , vol. 7, no. 1, pp. 16-19, 2013.

[18] J. Davis, "Setting up the role of emergency surgical nurse practitioner," Journal of Perioperative Practice, vol. 16, no. 3, pp. 144-147, 2006.

[19] B. E. Vaughn, G. Coppola, M. Verissimo et al., "The quality of maternal secure-base scripts predicts children's secure-base behavior at home in three sociocultural groups," International Journal of Behavioral Development, vol. 31, no. 1, pp. 65-76, 2007.

[20] T. T. Biss, L. R. Brandão, W. H. A. Kahr et al., "Clinical probability score and D-dimer estimation lack utility in the diagnosis of childhood pulmonary embolism," Journal of Thrombosis \& Haemostasis, vol. 7, no. 10, pp. 1633-1638, 2010.

[21] L. Zhang, L. Guan, and K. Zhou, "Stochastic machine scheduling to minimize waiting time related objectives with emergency jobs," Discrete Dynamics in Nature and Society, vol. 5, no. 11, pp. $1-5,2014$.

[22] T. Bektaş, J. F. Ehmke, H. N. Psaraftis, and J. Puchinger, "The role of operational research in green freight transportation," European Journal of Operational Research, vol. 274, no. 3, pp. 807-823, 2019.

[23] D. J. Forkenbrock, "Comparison of external costs of rail and truck freight transportation," Transportation Research Part A: Policy and Practice, vol. 35, no. 4, pp. 321-337, 2001.

[24] European Commission, "Directorate-General for Energy. A sustainable future for transport: towards an integrated, technology-led and user-friendly system," Tech. Rep., Office for Official Publications of the European Communities, 2009. 
[25] I. Harris, Y. Wang, and H. Wang, "ICT in multimodal transport and technological trends: Unleashing potential for the future," International Journal of Production Economics, vol. 159, pp. 88103, 2015.

[26] J. Flodén, F. Bärthel, and E. Sorkina, "Transport buyers choice of transport service - A literature review of empirical results," Research in Transportation Business and Management, vol. 23, pp. 35-45, 2017.

[27] D. Meers, C. Macharis, T. Vermeiren, and T. van Lier, "Modal choice preferences in short-distance hinterland container transport," Research in Transportation Business and Management, vol. 23, pp. 46-53, 2017.

[28] J. J. Winebrake and E. H. Green, "Environmental policy, decision making, and rebound effects in the U.S. trucking sector," Research in Transportation Business and Management, vol. 23, pp. 54-63, 2017.

[29] O. Al Enezy, E. van Hassel, C. Sys, and T. Vanelslander, "Developing a cost calculation model for inland navigation," Research in Transportation Business and Management, vol. 23, pp. 64-74, 2017.

[30] B. Lv, B. Yang, X. Zhu, and J. Li, "Operational optimization of transit consolidation in multimodal transport," Computers \& Industrial Engineering, vol. 129, pp. 454-464, 2019.

[31] V. Jayaraman and H. Pirkul, "Planning and coordination of production and distribution facilities for multiple commodities," European Journal of Operational Research, vol. 133, no. 2, pp. 394-408, 2001.

[32] J. K. Jolayemi and F. O. Olorunniwo, "A deterministic model for planning production quantities in a multi-plant, multiwarehouse environment with extensible capacities," International Journal of Production Economics, vol. 87, no. 2, pp. 99-113, 2004.

[33] Y. B. Park, "An integrated approach for production and distribution planning in supply chain management," International Journal of Production Research, vol. 43, no. 6, pp. 1205-1224, 2005.

[34] S. D. Ekşioğlu, H. Edwin Romeijn, and P. M. Pardalos, "Crossfacility management of production and transportation planning problem," Computers \& Operations Research, vol. 33, no. 11, pp. 3231-3251, 2006.

[35] A. Akbalik and B. Penz, "Comparison of just-in-time and time window delivery policies for a single-item capacitated lot sizing problem," International Journal of Production Research, vol. 49, no. 9, pp. 2567-2585, 2011.

[36] R. E. De Matta, V. N. Hsu, and C.-L. Li, "Coordinated production and delivery for an exporter," Institute of Industrial Engineers (IIE). IIE Transactions, vol. 47, no. 4, pp. 373-391, 2015.

[37] Z. Liang, Y. He, T. Wu, and C. Zhang, "An informative column generation and decomposition method for a production planning and facility location problem," International Journal of Production Economics, vol. 170, pp. 88-96, 2015.

[38] M. Darvish, H. Larrain, and L. C. Coelho, "A dynamic multiplant lot-sizing and distribution problem," International Journal of Production Research, vol. 54, no. 22, pp. 6707-6717, 2016.

[39] T. J. Choi, D. Li, and H. Yan, "Quick response policy with Bayesian information updates," European Journal of Operational Research, vol. 170, no. 3, pp. 788-808, 2006.

[40] X. Li, L. Sun, and J. Gao, "Coordinating preventive lateral transshipment between two locations," Computers \& Industrial Engineering, vol. 66, no. 4, pp. 933-943, 2013. 


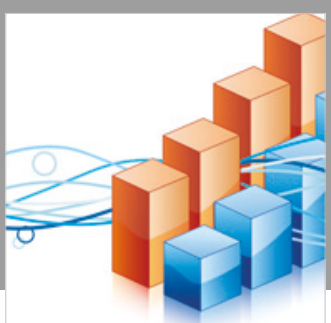

Advances in

Operations Research

\section{-n-m}
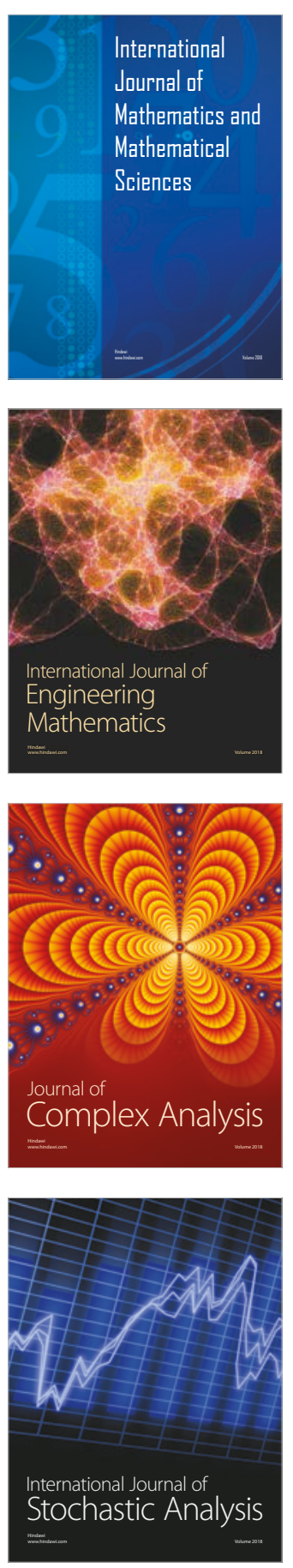
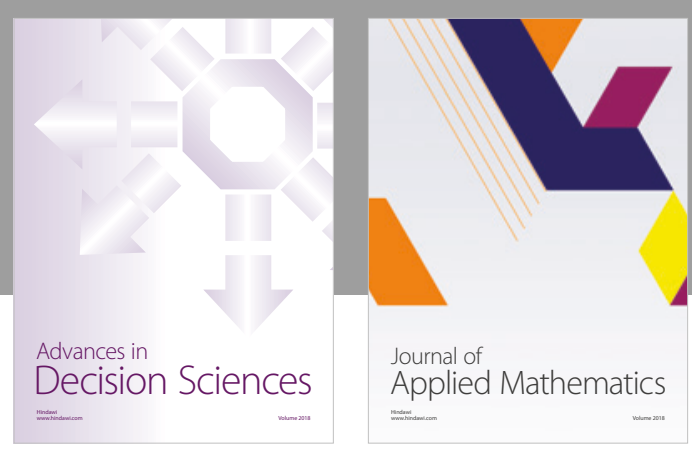

Journal of

Applied Mathematics
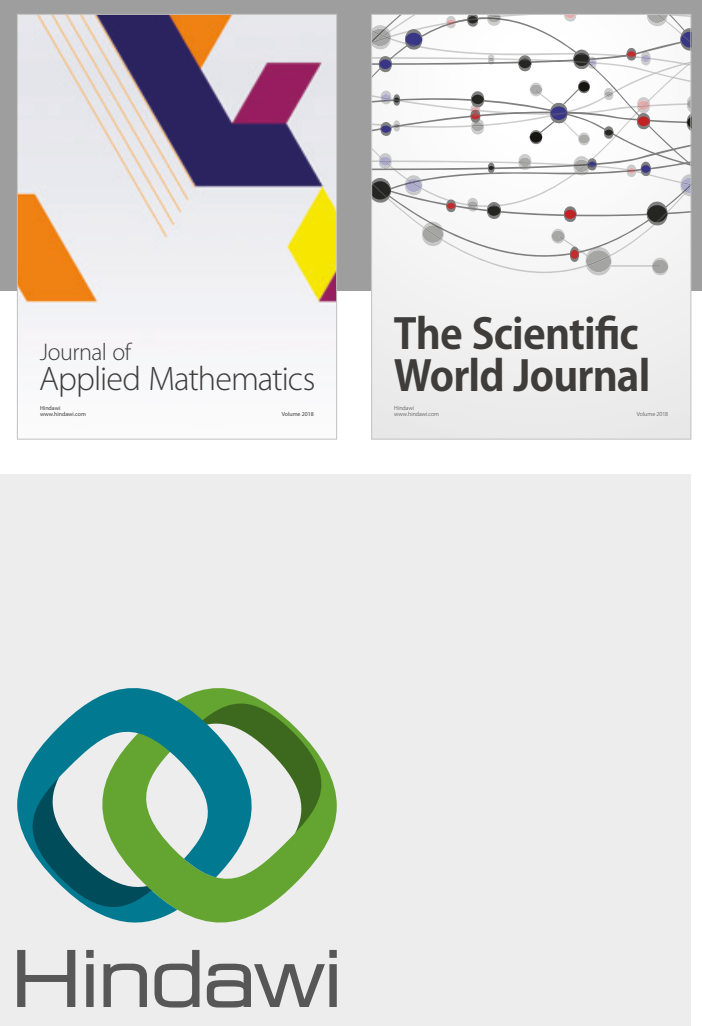

Submit your manuscripts at

www.hindawi.com

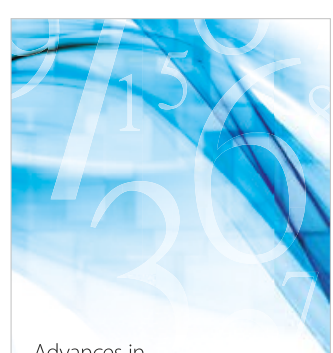

Advances in
Numerical Analysis
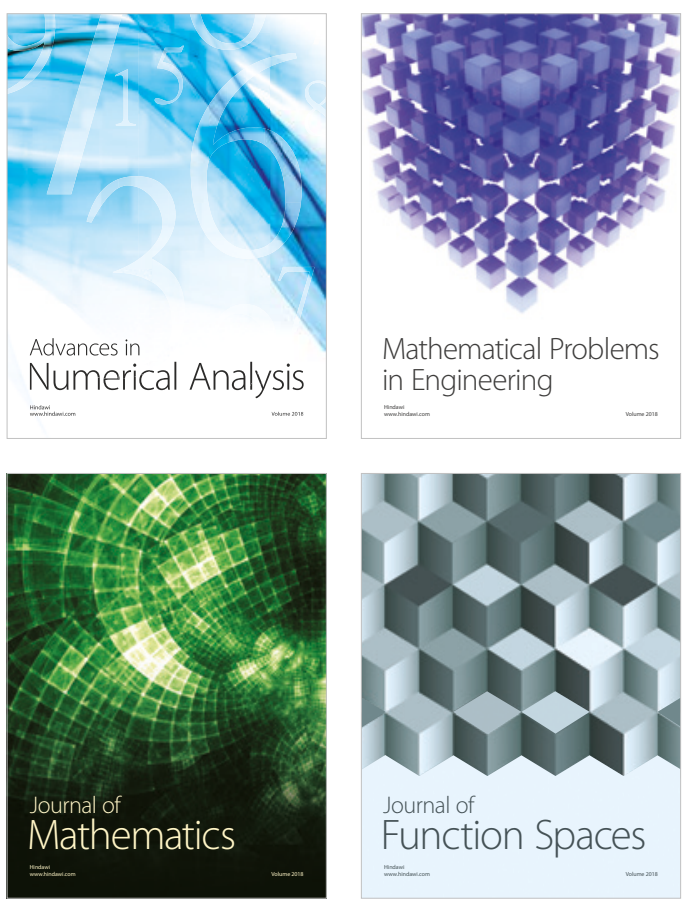

Mathematical Problems in Engineering

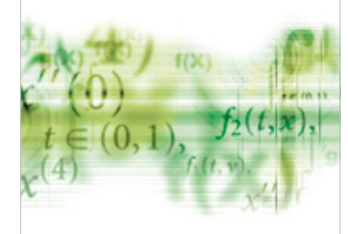

International Journal of

Differential Equations

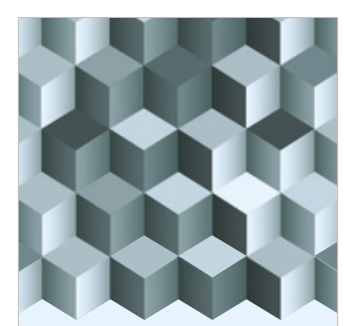

Journal of

Function Spaces

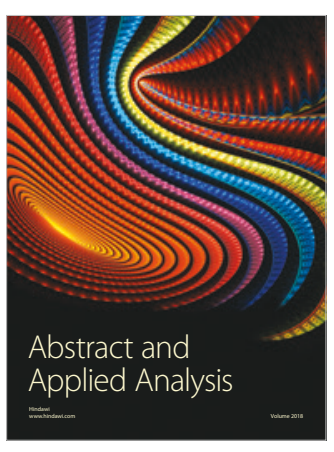

The Scientific

World Journal

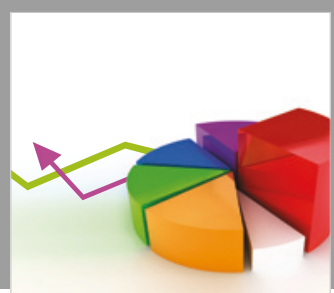

Journal of

Probability and Statistics
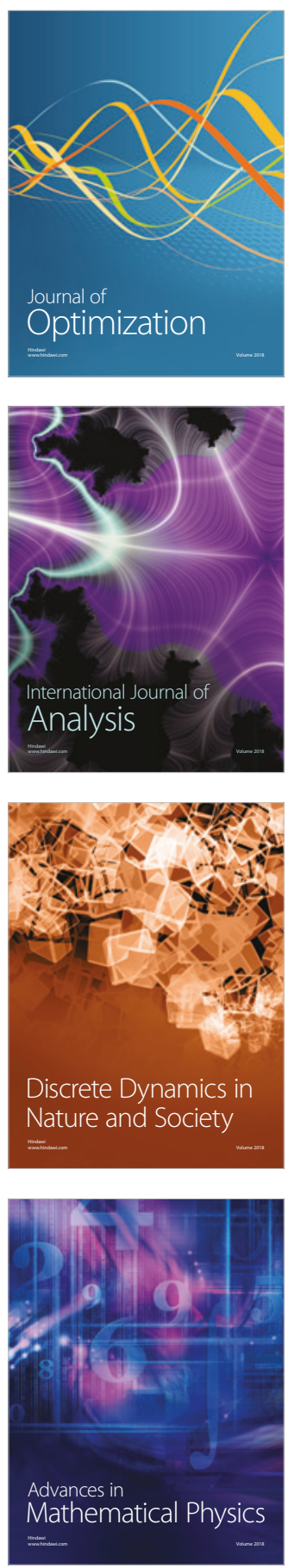